\title{
Chemical safety of black soldier fly larvae (Hermetia illucens), knowledge gaps and recommendations for future research: a critical review
}

\author{
S. Lievens ${ }^{1,2}$, G. Poma ${ }^{2}$, J. De Smet ${ }^{1}$, L. Van Campenhout ${ }^{1}$, A. Covaci ${ }^{2}$ and M. Van Der Borght ${ }^{1^{*}}$ \\ ${ }^{1}$ KU Leuven, Department of Microbial and Molecular Systems, Faculty of Engineering Technology, Lab4Food, Campus \\ Geel, Kleinhoefstraat 4, 2440 Geel, Belgium; ${ }^{2}$ Toxicological Centre, Department of Pharmaceutical Sciences, University of \\ Antwerp, Universiteitsplein 1, 2610 Wilrijk, Belgium; mik.vanderborght@kuleuven.be
}

Received: 14 July 2020 / Accepted: 24 November 2020

(c) 2021 Wageningen Academic Publishers

OPEN ACCESS C(1) (1)(2)

REVIEW ARTICLE

\begin{abstract}
Black soldier fly larvae (Hermetia illucens) (BSFL) are a promising protein source for the feed industry. They can be used to convert organic waste into valuable biomass, and due to their chemical composition, they are a valuable ingredient for several industrial sectors. To use BSFL as a feed ingredient, their chemical safety must be guaranteed. The composition of their rearing substrate is one of the crucial factors for safety, since it might introduce safety risks by bioaccumulation of various (in)organic compounds (e.g. toxic metals, mycotoxins, pesticides, etc.) in BSFL. Though several organic waste streams are potential and valuable rearing substrates for BSFL, the European Union currently does not allow their use due to safety knowledge gaps. This has prompted researchers to conduct several exposure experiments by artificially spiking chemicals to the rearing substrate of BSFL to investigate such risks. Here, we present a critical overview of the current body of literature on this topic and discuss the main findings, gaps, and recommendations for future research. Overall, BSFL do not seem to accumulate contaminants above the European feed legislation limits, except for certain metals (i.e. cadmium, lead, and zinc), which can jeopardise the chemical safety of the BSFL. For all compounds explored to date, except for cyromazine and pyriproxyfen, their presence in the substrate has no effect on the larval growth or survival rate. However, the remaining knowledge gaps concerning other potential hazardous chemicals (e.g. plasticisers, flame retardants, etc.) and their degradation pathways in BSFL still warrant an appropriate chemical safety assessment and can be a reason why several organic waste streams are not yet allowed to grow BSFL. The risks induced by the potential presence and accumulation of other chemical compounds requires further research to enable the safe exploitation of BSFL.
\end{abstract}

Keywords: chemical contaminants, organic waste streams, reared insects, bioaccumulation

\section{Introduction}

Due to the expected growth of the world population, which will reach 10 billion by 2050 (United Nations, 2017), the demand for food will rise proportionately (Shumo et al., 2019). To cover rising food requirements, meat production is expected to increase from 275 million tons in 2007 to 465 million tons by 2050 (Halweil, 2008; Shumo et al., 2019). This will in turn lead to a higher need for protein sources for feed, e.g. soybeans, which will cause more deforestation and intensification of land use (Barona et al., 2010; Shumo et al., 2019). Therefore, to keep meat as a protein source for humans, a more sustainable production process of livestock is required. The black soldier fly (BSF) (Hermetia illucens, Linnaeus 1758, order of Diptera, Stratiomyidae family) has been proposed as an alternative for soybean meal in animal feed (Stamer, 2015), and its use is already allowed for aquaculture in Europe (European Commission, 2017; Lähteenmäki-Uutela et al., 2017).

The BSF is a species originally native to the (sub)tropical and warm climate of America, but currently widespread in all (sub)tropical regions around the globe. BSFs are nonpest, wasp-like, adaptable, saprophagous insects, about 13 to $20 \mathrm{~mm}$ in length (Rohacek and Hora, 2013; Tomberlin et al., 2006), while their larvae can be larger and grow up 
to $27 \mathrm{~mm}$ with a width of $6 \mathrm{~mm}$. Black soldier fly larvae (BSFL) have chewing mouthparts, whereas adult forms have non-functional, sponge-like mouthparts (Al-Qazzaz et al., 2016; Diclaro and Kaufman, 2009; Oliveira et al., 2016). The BSF has a 40- to 45-day holometabolous life cycle, including a complete metamorphosis (Figure 1) (De Smet et al., 2018; Purschke et al., 2017).

Another crucial factor that has led BSFL to become one of the most interesting insects for bioconversion on an industrial scale is the ease of rearing, as the larvae are able to grow on several typologies of substrates, ranging from organic side streams to manure (Čičková et al., 2015). Currently, a considerable volume of organic waste streams is anaerobically digested to produce biogas, representing $72 \%$ of the total produced biogas (625 petajoule) in Europe (Kampman et al., 2017). Using these waste streams as a substrate for BSFL rearing would result in a higher waste management hierarchy (reuse instead of energy recovery), which is more preferable (Environmental Protection Agency, 2020).

BSFL are not only suitable to convert organic streams, but they also turn these rearing substrates into valuable biomass such as proteins, fats, and chitin (Caligiani et al., 2018). Both proteins and fats are suitable feed sources for several animals like, for instance, broilers, pigs and aquaculture (Diener et al., 2009; Kim et al., 2020; Kroeckel et al., 2012; Makkar et al., 2014; Maurer et al., 2016). Despite the high energetic value of the fats, the fatty acid profile is not optimal for some fish species. BSFL contain a high amount of medium-chain saturated fatty acids (e.g. lauric acid, C12:0) (Kim et al., 2020), while marine fish have a greater requirement for omega- 3 fatty acids (e.g. eicosapentaenoic acid and docosahexaenoic acid) (Craig et al., 2017), which have to be taken into account when feeding aquaculture with fat of BSFL. In addition to the use of fat for feed, the fat extracted from BSFL can also be used to produce biodiesel, cosmetics, ..., and surfactants (Li et al., 2011; Verheyen et al., 2018). Chitin, a building block of the insect's exoskeleton, can be converted into chitosan, an economically valuable non-toxic compound with beneficial biochemical properties (e.g. biodegradable, antimicrobial, ..., and biocompatible) (Elieh-Ali-Komi and Hamblin, 2016; Smets et al., 2020). To fully utilise the BSFL's potential reared on organic waste streams, it is imperative to determine their safety aspects in detail. Although the microbiological safety aspects are evidently of fundamental importance, this review article focuses solely on the chemical safety aspects. A synthesis of the literature concerning the microbiological aspects of the BSF is presented in the reviews compiled by Vandeweyer et al. (in press), and Wang and Shelomi (2017).

Along with a short introduction on the European legislation and the chemical composition of BSFL, several studies regarding rearing experiments on BSFL with artificially spiked substrates containing hazardous chemical compounds will be discussed. We will also describe potential knowledge gaps and recommend new directions for future research.

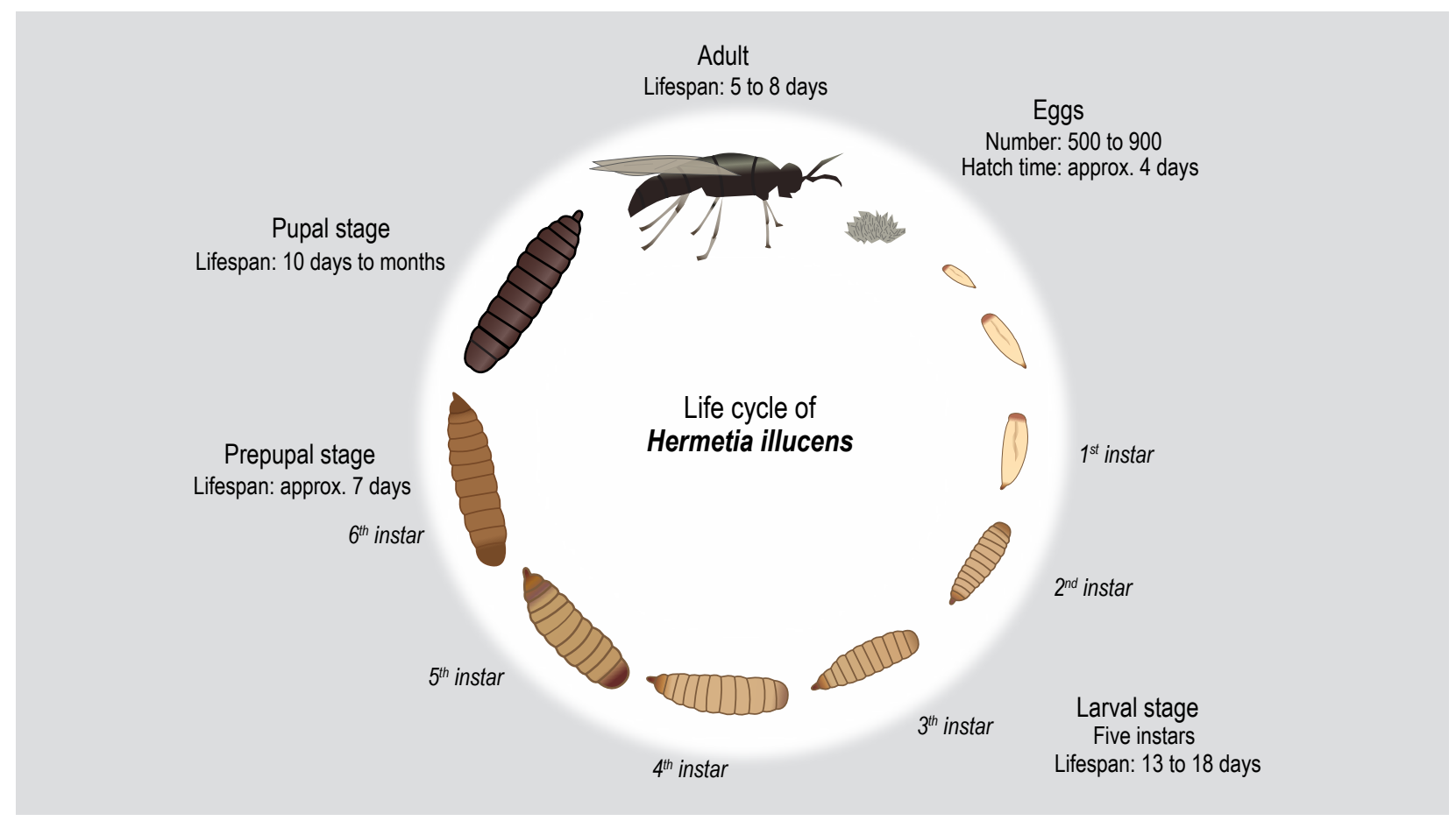

Figure 1. The life cycle of the black soldier fly (Hermetia illucens) (modified from De Smet et al., 2018). 


\section{Legislation for farming and using black soldier fly larvae as feed ingredient}

The increasing interest towards industrially reared insects is supported by their documented nutritional quality and their potential as a cornerstone of a circular economy (Imathiu, 2020; Lähteenmäki-Uutela et al., 2017). Rearing substrates may contain hazardous contaminants and are susceptible to accumulate in various insect species, which in turn raises questions and concerns about the chemical safety (Imathiu, 2020). The current legislation that applies to BSFL can generally be divided into two parts. The first part reflects the legislation on farming BSFL, while the other part describes the legislation on the use of BSFL as a feed ingredient or as a source of biochemical compounds.

\section{Legislation regarding farming of black soldier fly larvae}

Insects are classified as farmed animals and thus they are also subjected to the legislation of traditional farmed animals (Federal Agency for the Safety of the Food Chain, 2019; International Platform of Insects for Food and Feed, 2020). The EU imposed restrictions for feed used for animals, which can be utilised as food, feed or other derivatives (Lähteenmäki-Uutela et al., 2017). According to the EU Regulation 2016/429, farmed animals, including insects, may only be fed with vegetable matter, except for a few animal protein sources being milk, eggs, honey, rendered fat and non-ruminant blood products. It is prohibited to feed them with animal by-products like slaughterhouse products, manure, or waste streams like household waste (European
Commission, 2009, 2016b; Federal Agency for the Safety of the Food Chain, 2019). Nevertheless, BSFL grow well on such organic waste streams (Čičková et al., 2015). Hence, this insect species could be used to process low grade residual organic streams, thereby obtaining valuable larvae, provided the larvae are safe to use as feed ingredient or raw material. In case of BSFL being imported from outside the EU, to act as animal feed, they will be subject to a veterinary assessment according to Regulation 2019/2007. In Annex one of this regulation, the animals subject to this assessment are listed, including insects (European Commission, 2019). As previously mentioned insects are classified as farmed animals, hence it is forbidden to rear insects on waste streams (e.g. manure), but in other countries outside the EU it might be different. To assess the chemical safety of BSFL as feed ingredient, the legislation on the maximum allowed concentration of chemical compounds in feed needs to be explained. The European Commission has laid down maximum and guidance levels of several compounds allowed to feed different farmed animals, and Table 1 shows the maximum and the recommendation levels of the already investigated compounds for BSFL to date. Since these maximum levels depend upon the farmed animal, a range is shown for each compound (European Commission, 2002, 2006, 2013, 2016a, 2020).

If it is proven that the larvae meet the imposed safety standards as a feed ingredient if they are reared on organic waste streams that are currently not approved as animal feed, it may be justified to amend the legislation in order to upgrade these undervalued waste streams as BSFL feed.

Table 1. Overview of the maximum and guidance ${ }^{*}$ levels of selected chemicals in animal feed. The selection of these chemicals is based upon the studies that were found investigating their presence in black soldier fly larvae.

\begin{tabular}{|c|c|c|c|}
\hline Compound category & Compound & $\begin{array}{l}\text { Maximum level in feed (mg/kg) } \\
\text { with a moisture content of } 12 \%\end{array}$ & Reference \\
\hline \multirow[t]{5}{*}{ Metals } & Arsenic & $2-100$ & European Commission, 2013 \\
\hline & Cadmium & $0.5-30$ & European Commission, 2013 \\
\hline & Lead & $5-400$ & European Commission, 2013 \\
\hline & Mercury & $0.1-0.5$ & European Commission, 2002 \\
\hline & Zinc & $120-200$ & European Commission, 2016a \\
\hline \multirow[t]{5}{*}{ Mycotoxins } & Aflatoxin $B_{1}$ & $0.005-0.03$ & European Commission, 2002 \\
\hline & Deoxynivalenol & $0.9-12^{*}$ & European Commission, 2006 \\
\hline & Fumonisin $\mathrm{B}_{1}+\mathrm{B}_{2}$ & $5-60^{*}$ & European Commission, 2006 \\
\hline & Ochratoxin A & $0.05-0.25^{*}$ & European Commission, 2006 \\
\hline & Zearalenone & $0.1-3^{*}$ & European Commission, 2006 \\
\hline \multirow[t]{7}{*}{ Pesticides } & Azoxystrobin & 0.01 & European Commission, 2020 \\
\hline & Chlorpyrifos & 0.01 & European Commission, 2020 \\
\hline & Chlorpyrifos-methyl & 0.01 & European Commission, 2020 \\
\hline & Cyromazine & 0.01 & European Commission, 2020 \\
\hline & Pirimiphos-methyl & 0.01 & European Commission, 2020 \\
\hline & Propiconazole & 0.01 & European Commission, 2020 \\
\hline & Pyriproxyfen & 0.05 & European Commission, 2020 \\
\hline
\end{tabular}


In addition, if BSFL are fed with substrates containing hazardous chemical compounds like mycotoxins, having a concentration above the currently allowed maximum level and it is demonstrated that BSFL do not accumulate such compounds or even degrade them to non-toxic derivatives, then these larvae potentially can be used as feed ingredient for farmed animals. Therefore, a legislative alignment could be made to upgrade the aforementioned organic substrates as feed for reared BSFL.

\section{Legislation regarding insects as feed ingredient}

Since BSFL are considered as both farmed animals and a feed ingredient, the legislation of the latter also needs to be clarified. Due to the feed ban rules (Regulation No 999/2001; European Commission, 2001) of the EU as a result of the bovine spongiform encephalopathy outbreak, processed animal proteins are prohibited to be used as feed for ruminants and monogastric animals. An amendment for aquaculture was made allowing to feed them with processed animal proteins of non-ruminants, stated in both regulations, regulation 2017/893 and the consolidated text of Regulation 999/2001 (European Commission, 2001, 2017; Lähteenmäki-Uutela et al., 2017). Additionally, whole living insects and insect-derived fats are admitted, and recently Commission Regulation No 2017/893 also permits the use of proteins derived from seven insect species, including BSFL, in feed for aquaculture animals (European Commission, 2017; Lähteenmäki-Uutela et al., 2017). To date, these insects are not allowed as a feed ingredient for other farmed animals, like pigs or poultry.

\section{Chemical composition}

Since the BSFL's chemical composition can impact the bioaccumulation of chemicals, it must be considered as a potential factor affecting their chemical safety. For instance, lipophilic compounds can easily accumulate in the insect's fat body (Sotnichenko et al., 2019). Hence, a higher fat content might cause a higher bioaccumulation potential of harmful lipophilic compounds.

The dry weight of the larvae and prepupae varies respectively between $12.7-38.8 \%$ and $8.4-41.0 \%$ (Finke, 2013; Spranghers et al., 2017; St-Hilaire et al., 2007), and is usually determined either by lyophilisation or oven drying (Abduh et al., 2018; Meneguz et al., 2018). The protein content (based on dry matter) of the larvae, prepupae and pupae varies respectively between 8.6-56.0\%, 13.0-45.1\% and 31.3-46.2\% (Abduh et al., 2018; Al-Qazzaz et al., 2016; Ottoboni et al., 2018; Smets et al., 2020; Spranghers et al., 2017; Liu et al., 2017). Whereas the protein content was calculated by multiplying the nitrogen content with a conversion factor (4.76-6.25), the nitrogen content itself was determined according to the Kjeldhal or Dumas method (Caligiani et al., 2018; Janssen et al., 2017; Meneguz et al.,
2018). Janssen et al. (2017) have shown that the nitrogen to protein conversion factor is 4.76 , considering the presence of non-protein nitrogen in the larvae. The accuracy of this factor is of major importance as the nitrogenous chitin, which is present in the insect exoskeleton, is nearly indigestible in some farm animal species depending on the availability of specific chitin degrading enzymes (e.g. acidic chitinase) (Tabata et al., 2018). The fat content (based on dry matter) of the larvae, prepupae and pupae varies respectively between $8.1-41.0 \%, 11.8-37.1 \%$ and $7.2-39.8 \%$ (Caligiani et al., 2018; Kroeckel et al., 2012; Liland et al., 2017; Smets et al., 2020; Liu et al., 2017). This wide variation of the fat content is likely due to the different substrates used to rear BSFL (Tschirner and Simon, 2015) and the different methods of analysis applied, like a Soxhlet, Folch or cold extraction (Cullere et al., 2018; Spranghers et al., 2017; Tschirner and Simon, 2015). The exoskeleton of the BSFL contains chitin (Spranghers et al., 2017), with a content (based on dry matter) of the larvae, prepupae and pupae varying respectively between $5.3-6.2 \%, 4.7-9.6 \%$ and $6.3 \%$ (Kroeckel et al., 2012; Meneguz et al., 2018; Smets et al., 2020). The chitin contents were determined gravimetrically or by means of gas or liquid chromatography and required a pre-treatment, and, depending upon the method applied, also a derivatisation of the samples. The reaction conditions under which the pre-treatments and derivatisations were carried out varied according to the study (Caligiani et al., 2018; Hondt et al., 2020; Liu et al., 2012; Smets et al., 2020; Spranghers et al., 2017).

From the data collected, it is evident that the larvae do have an excellent chemical composition to be used as feed ingredient (Makkar et al., 2014), but also that the experimental values differ from study to study. These differences might be caused by the various rearing methods and substrate compositions which were used, but also due to the methods of analysis applied. Hence, the development and use of standardised rearing and analytical methods is required to allow inter-study comparisons. The standardisation of both the rearing and analytical methods for the determination of the chemical composition of insects is therefore strongly recommended by the authors and should be performed under the auspices of an internationally recognised organisation, such as respectively the European Federation of Animal Science (EAAP), and the AOAC International, the International Organization for Standardization, or an equivalent.

\section{Influence of various chemicals on the chemical safety of black soldier fly larvae}

During the rearing phase, the bioaccumulation of some chemical compounds might pose a safety risk. A reliable parameter to estimate the fraction of a compound which is taken up and stored faster than it is metabolised or excreted by an organism is represented by the bioaccumulation factor 
(BAF), i.e. the ratio of a compound's amount in the biomass of an organism compared to its amount in the substrate (Weisbrod et al., 2007).

Currently, BSFL are not only reared on organic waste streams, going from super market and restaurant waste to animal and even humane manure, in low and middleincome countries (Da Silva and Hesselberg, 2020; Diener et al., 2009) but they are also attracting a growing interest from several companies in prosperous countries due to their high potential and sustainability. However, in the European Union, these substrates are not allowed due to a lack of knowledge concerning the associated chemical and microbiological risks (Biancarosa et al., 2018). As mentioned above, in insect rearing, the substrate is the primary source of chemical safety risks. Due to this key role, the chemical safety, such as the potential accumulation of (in)organic compounds, requires extensive research (Finke et al., 2015).

\section{Metals}

Metals are toxic for various plants and animals above a certain concentration, but these levels depend upon the organism and the metal. In contrast, some metals (e.g. zinc, iron and copper) are essential in low concentrations for metabolic processes (Gold et al., 2018; Pandey and Madhuri, 2014; Yadav, 2010). Due to the known toxicity of numerous metals for several organisms, they can also be toxic for BSFL, as shown in several studies. In general, the experimental setups implied that the larvae were reared on substrates to which metals were added in different concentrations (Table 2) (Biancarosa et al., 2018; Diener et al., 2015; Gao et al., 2017; Purschke et al., 2017; Van Der

Table 2. Overview of the initial feed concentration, final residue concentration and larval concentration (based on dry matter) of all investigated compounds.

\begin{tabular}{|c|c|c|c|c|c|}
\hline Compound & Compound class & $\begin{array}{l}\text { Feed concentration } \\
(\mathrm{mg} / \mathrm{kg})^{1}\end{array}$ & $\begin{array}{l}\text { Residue concentration } \\
(\mathrm{mg} / \mathrm{kg})^{2}\end{array}$ & $\begin{array}{l}\text { Larval concentration } \\
(\mathrm{mg} / \mathrm{kg})\end{array}$ & Reference $^{3}$ \\
\hline Arsenic & metal & $0.08-36$ & 3.8 & $0.08-23$ & $A, B, F$ \\
\hline Cadmium & metal & $0.09-80$ & $1.8-155.10$ & $0.41-502.16$ & $A, B, C, D, E, F$ \\
\hline Chromium & metal & $15.2-300$ & 19.9 & 3.4 & $\mathrm{C}, \mathrm{F}$ \\
\hline Lead & metal & $0.07-142.9$ & $7.8-267.9$ & $0.06-35.6$ & $A, B, D, F$ \\
\hline Mercury & metal & $0.002-0.2$ & 0.3 & $<\mathrm{LOQ}-0.1$ & $\mathrm{~B}, \mathrm{~F}$ \\
\hline Nickel & metal & 15.2 & 19.7 & 4.2 & $\mathrm{~F}$ \\
\hline Zinc & metal & $50-2,044$ & $336.04-3,313$ & $373.25-866$ & $\mathrm{D}, \mathrm{E}$ \\
\hline Aflatoxin $B_{1}$ & mycotoxin & $0.0133-0.415$ & $<\mathrm{LOQ}-0.0109$ & $<L O Q$ & $F, G$ \\
\hline Aflatoxin $B_{2}$ & mycotoxin & 0.0026 & $<L O Q$ & $<L O D$ & $\mathrm{~F}$ \\
\hline Aflatoxin $\mathrm{G}_{2}$ & mycotoxin & 0.007 & $<L O Q$ & $<L O D$ & $\mathrm{~F}$ \\
\hline Deoxynivalenol & mycotoxin & $0.00063-0.779$ & $<$ LOD-1.473 & $<L O Q$ & $\mathrm{~F}, \mathrm{H}, \mathrm{I}$ \\
\hline Fumonisin $\mathrm{B}_{1}$ & mycotoxin & $0.452-0.573$ & $<\mathrm{LOD}-0.951$ & $<L O D$ & I \\
\hline Fumonisin $B_{2}$ & mycotoxin & $0.348-0.441$ & $<$ LOD-0.344 & $<L O D$ & I \\
\hline Ochratoxin A & mycotoxin & 0.0394 & $<L O Q$ & $<L O D$ & $\mathrm{~F}$ \\
\hline Zearalenone & mycotoxin & $<$ LOD-0.1304 & $<$ LOD-0.334 & $<L O D$ & $\mathrm{~F}, \mathrm{I}$ \\
\hline Chlorpyrifos & insecticide & 0.4 & 0.228 & 0.006 & $\mathrm{~F}$ \\
\hline Chlorpyrifos-methyl & acaricide and insecticide & 0.4 & 0.068 & $<L O Q$ & $\mathrm{~F}$ \\
\hline Pirimiphos-methyl & acaricide and insecticide & 0.4 & 0.172 & 0.001 & $\mathrm{~F}$ \\
\hline Azoxystrobin & fungicide & $2.4-4.6$ & n.a. & n.a. & $\mathrm{J}$ \\
\hline Propiconazole & fungicide & $3.2-14.1$ & n.a. & n.a. & J \\
\hline Cyromazine & insecticide & $0.0585-1.5^{*}$ & n.a. & n.a. & $\mathrm{K}$ \\
\hline Pyriproxyfen & insecticide & $0.0316-1,827^{*}$ & n.a. & n.a. & $\mathrm{K}$ \\
\hline Carbamazepine & anti-epileptic & $1.8-1.9$ & n.a. & n.a. & J \\
\hline Roxithromycin & antibiotic & $5.8-5.9$ & n.a. & n.a. & $\mathrm{J}$ \\
\hline Trimethoprim & antibiotic & $5.9-9.9$ & n.a. & n.a. & J \\
\hline
\end{tabular}


Fels-Klerx et al., 2016). During the rearing experiments, the growth performance and development time of the insects were assessed.

Diener et al. (2015) observed that, if the larvae were exposed to increasing concentrations of cadmium, lead and zinc, a longer time was required for BSFL to go from hatching to the prepupal stage, although this result was not statistically significant. Surprisingly, prepupae reared on substrates spiked with cadmium were found to have a significantly higher body mass in comparison with larvae reared on the reference substrate, while no differences occurred in the presence of zinc or lead (Diener et al., 2015).

In addition, the accumulation patterns of the metals need to be examined (Figure 2). During larval development, the concentration of some metals (e.g. cadmium, lead and zinc) increased over time, resulting in a BAF above one (Diener et al., 2015; Purschke et al., 2017; Van Der Fels-Klerx et al., 2016). Cadmium is a toxic non-essential, non-biodegradable, persistent, mobile element that can accumulate in BSFL up to a sevenfold concentration, due to the similarity in ionic radii between cadmium and calcium allowing them to pass easily through calcium channels (Biancarosa et al., 2018; Diener et al., 2015; Gao et al., 2017). Besides issues provided by cadmium, the accumulation of zinc into the BSFL biomass (BAF>1) might in the future cause problems with its approval as animal feed, as a further reduction of the allowed zinc content in animal feed is being considered in the EU (European Food Safety Authority, 2017). Chromium and lead gave contradictory results. Some studies showed that these metals accumulate in BSFL (Gao et al., 2017; Purschke et al., 2017), while others observed no accumulation in the BSFL's body, but immobilisation in the exoskeleton (Biancarosa et al., 2018; Diener et al.,
2015; Purschke et al., 2017; Van Der Fels-Klerx et al., 2016). Arsenic concentrations in BSFL were found to decrease by starving the larvae, which indicates that it was present in the gut contents and does not accumulate in the organism. This result is reflected in a BAF below one and thus will probably not constitute a chemical hazard if the larvae are starved (Van Der Fels-Klerx et al., 2016). The findings show that it is recommended to monitor cadmium, lead, and zinc concentrations in waste streams to use them safely as a substrate to rear BSFL.

Since the prepupae and pupae do not eat, BAFs are likely to decrease in these life stages (Figure 2). It also seems that BSFL can excrete specific elements during the metamorphosis into the pupal life stage. Metals like cadmium and chromium, which were accumulated in the exoskeleton, are largely expelled with the exuviae, while they are mainly found in the body instead of the moult during the larval and prepupal stage (Bulak et al., 2018; Gao et al., 2017). As a result, the chemical safety is likely to differ between the BSF life stages.

The impact of metals on several BSFL performance parameters has been studied already, but data regarding the hatchability, although important, are currently still lacking. The hatchability determines the amount of offspring and thus the stability of the life and rearing cycle, but the influence of metals on this parameter and the next generation is still unexplored (Gao et al., 2017; Purschke et al., 2017). In addition, the interactions between effects of several metals might cause synergistic effects, which have been insufficiently studied so far. Up till now, to the best of our knowledge, only one article of Yu et al. (2017) describes the combined effect of metals and it seems that BSFL show a high tolerance to such effects. However,

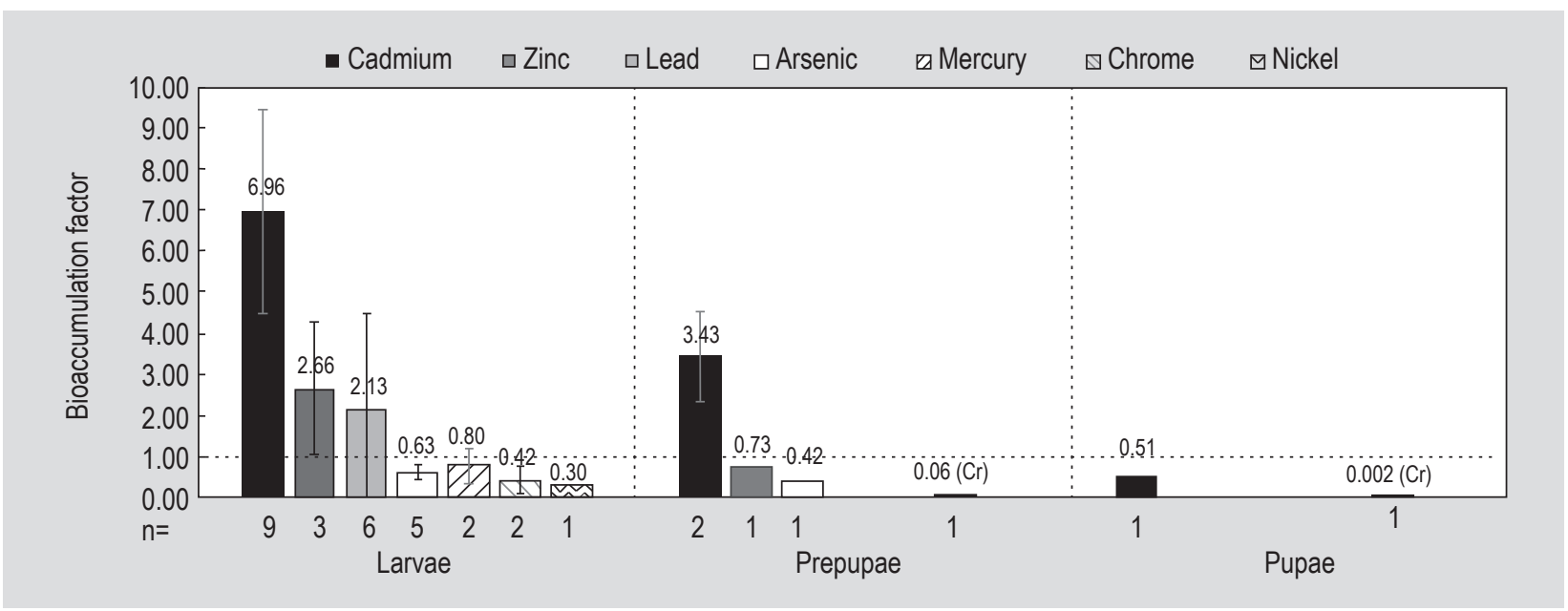

Figure 2. Bioaccumulation factors (BAF) of several metals with their standard deviation (only for the results having more than one replicate) for black soldier fly larvae, prepupae and pupae. The dotted line indicates BAF=1. The dataset is generated with different replicates for each metal, indicated by the number of replicates $(n)$ below the graph. The dataset is based on Biancarosa et al. (2018), Bulak et al. (2018), Diener et al. (2015), Gao et al. (2017), Purschke et al. (2017) and Van Der Fels-Klerx et al. (2016). 
spiking the substrates with a mixture of several metals/ metalloids $(\mathrm{B}, \mathrm{Hg}, \mathrm{Ni}, \mathrm{Pb})$ seems to reduce their final weight, while a combination of other metals $(\mathrm{Cd}, \mathrm{Cr}, \mathrm{Cu}, \mathrm{Hg}$ and $\mathrm{Zn})$ slightly reduced the survival rate (Yu et al., 2017), but this effect needs to be confirmed in further research. Currently, it is known that several metals (e.g. cadmium and lead) are immunotoxins and induce immunosuppression, resulting in a reduction of the number of haemocytes in the common housefly larvae (Musca domestica). Haemocytes are the cells present in the haemolymph (extracellular liquid) of insects, and provide the cell-mediated immune response, as well as the storage, distribution, regulation, and metabolism of molecules. A reduction of these cells can cause decrease of survival of the common housefly ( $M$. domestica) (Borowska and Pyza, 2011). Similar investigation is currently lacking for H. illucens.

\section{Mycotoxins}

Mycotoxins are produced by moulds, which grow on various matrices, like fruits, vegetables, and decaying material. If feed is moulded and if mycotoxins were produced during mould growth, larvae potentially accumulate these mycotoxins. The accumulation of mycotoxins can lead to public health issues by induction of carcinogenic effects, if the ingested mycotoxins are listed in group one (carcinogenic to humans) by the International Agency for Research on Cancer (Ostry et al., 2017), or it can render the biochemicals extracted from the larvae useless (Diener et al., 2015; Imathiu, 2020; Wild and Gong, 2010; WHO, 2020). Therefore, the effect(s) induced by the potential accumulation of mycotoxins on the larvae are crucial for the feed industry (Bosch et al., 2017). So far, no influence of exposure to mycotoxins, shown in Table 2 , has been observed on larval growth performance or survival rate, probably due to limited accumulation of various mycotoxins, resulting in concentrations below the maximum/guidance values prescribed by the European feed law. In fact, the mycotoxin concentration in the residue (which is the remaining substrate along with excretion products of the BSFL) is in general even reduced compared to the substrate due to the presence of BSFL, except in one case of zearalenone (Bosch et al., 2017; Gulsunoglu et al., 2019; Leni et al., 2019; Purschke et al., 2017). Zearalenone can increase in the residue, possibly by the extractability of the compound. BSFL degrade the substrate while growing on it, which might increase the extractability of the mycotoxins (Leni et al., 2019). For the other mycotoxins, the degradation mechanisms currently remain unknown. Furthermore, aflatoxin B1, which can be converted by other insect species like the navel orangeworm (Amyelois transitella) to aflatoxicol by the NADPH-dependent enzyme aflatoxin B1 aldehyde reductase, along with aflatoxin M1 and aflatoxin B2a, has not been found in the BSFL (Bosch et al., 2017). It seems that BSFL are able to metabolise these compounds through a currently unknown mechanism
(Bosch et al., 2017). Also the BSFL seem not to accumulate several mycotoxins above the maximum limits imposed by the European legislation. In addition, there is also a lack of research about the bioaccumulation patterns and the influence of other mycotoxins, like for instance patulin, because it mainly appears in fruit and vegetable waste, which can be transmitted to BSFL (Moake et al., 2005). Patulin might not yet be investigated due to their absence in the feed legislation. Besides patulin, T-2 and HT-2 mycotoxins, also listed in European legislation, are produced by several fungi (e.g. Fusarium and Myrothecium) resulting them in important mycotoxins in the agriculturally sector due to their presence in grains like for instance wheat (Adhikari et al., 2017; Canady et al., 2001).

\section{Pesticides}

Pesticides (e.g. insecticides, herbicides, ..., acaricides) can possibly accumulate in BSFL, and if the larvae are used as a feed ingredient, transferred along the feed and food chain (Imathiu, 2020). A possible health outcome following the accumulation of pesticides in BSFL is linked to the disruption of their life cycle leading to a higher mortality rate (Tomberlin et al., 2002). Various pesticides (e.g. organochlorines, organophosphates, carbamates, etc.) also suppress the immune system of humans and animals (Repetto and Baliga, 1997). Due to the risk of feed contamination, the influence of pesticides on BSFL and their bioaccumulation needs to be investigated.

Exposure studies with several pesticides were performed (Table 2) to investigate their influence on BSFL and their BAFs (Lalander et al., 2016; Purschke et al., 2017; Tomberlin et al., 2002). The investigated pesticides (chlorpyrifos, chlorpyrifos-methyl, pirimiphos-methyl, azoxystrobin, and propiconazole) did not accumulate in the biomass of the BSFL and did not affect growth, indicating that there are no chemical safety hazards. These pesticides were even degraded in the substrate, but the degradation mechanism is still unknown (Lalander et al., 2016; Purschke et al., 2017). In addition, the $\mathrm{LD}_{50}$ of cyromazine for BSFL was determined and was found to lie between 0.25 and 0.28 $\mathrm{mg} / \mathrm{kg}$ substrate, including a $50 \%$ reduction of the living BSFL weight at a concentration of $0.296 \mathrm{mg}$ cyromazine/ $\mathrm{kg}$ substrate. Whereas the BSFL weight increased when pyriproxyfen was spiked up to $58 \mathrm{mg} / \mathrm{kg}$ substrate, higher concentrations caused a decrease of their weight, but the cause of these variations is not known (Tomberlin et al., 2002). In addition to the influence of pesticides on BSFL, De Paepe et al. (2019) developed an analytical screening method to determine several pesticides, (veterinary) drugs and mycotoxins simultaneously in insect matrices. De Paepe et al. (2019) measured the concentration of a range of pesticides in commercially available and for research purposes reared insects, namely the lesser mealworm (Alphitobius diaperinus), the BSF (H. illucens), the house 
cricket (Acheta domesticus) and the migratory locust (Locusta migratoria), but only one out of the 25 investigated pesticides (isoproturon) was found. Due to the limited research that was conducted, still many questions remain about the influence and/or accumulation of the investigated, as well as the not yet explored pesticide classes in BSFL (e.g. organochlorine compounds).

\section{Pharmaceutical compounds}

In addition to the metals, mycotoxins, and pesticides, also the effect of some pharmaceutical compounds (Table 2) on BSFL were investigated (Lalander et al., 2016). During exposure studies, Lalander et al. (2016) spiked three pharmaceutical compounds including trimethoprim to the substrate (Table 2) and detected them in the BSFL after a few days ( 3 and 12), with a respective concentration of $24 \mathrm{ng} / \mathrm{g}$ and $6 \mathrm{ng} / \mathrm{g}$ (based on wet weight). Hence, it appears that BSFL take up trimethoprim. On the other hand, at the end of the rearing cycle trimethoprim was below the detection limit, meaning that it was excreted or degraded. The other compounds (carbamazepine and roxithromycin) were not detected in the larvae, and both growth performance and survival rate remained unaffected. Interestingly, all investigated compounds were reduced at the end of the rearing period, while they are persistent and difficult to degrade in aerobic systems like wastewater treatments (Lalander et al., 2016). It appears that these pharmaceutical compounds do not adversely affect the chemical safety of the BSFL if they were used as feed component. Lalander et al. (2016) assumed that their degradation would rather take place in the substrate, likely mediated by microbiological activity attributed to the BSFL and/or associated with the substrate. Besides the lack of knowledge about the degradation pathway of the pharmaceuticals, the effect of other chemicals (e.g. hormones, commonly used antibiotics, etc.) was not studied thus far, which impends new research questions about the chemical safety of BSFL reared on substrates containing these compounds.

\section{Other compounds and knowledge gaps}

Various compounds can be simultaneously present in waste streams used as substrate for BSFL, leading to other loopholes of their chemical safety. Apart from the investigated chemical classes mentioned above, also other groups of compounds need to be evaluated. Recently, there is increased concern about the presence and effects of plastics in the environment. BSFL grow quickly on organic waste streams, but this type of substrates frequently contains plastics, microplastics, and possibly additive chemicals from food packaging materials (e.g. plasticisers, flame retardants, etc.). Except for a preliminary study performed by the authors of this review, the effects of these materials and compounds on BSFL and their chemical safety have not yet been investigated. During our preliminary study, BSFL were exposed to polystyrene, containing only low amounts of additives (i.e. bis(2-ethylhexyl) adipate), resulting in a limited chance of accumulation of the additives in the larvae. According to the accumulation assessments of these additives in BSFL, no correlation was found between the additives present in the substrate and their accumulation pattern in the BSFL (unpublished results).

Currently, some insect species (Tenebrio molitor and Plodia interpunctella) are known to be capable of degrading plastics (i.e. polystyrene and polyethene) to a certain extent (Brandon et al., 2019; Yang et al., 2014, 2015a,b, 2018). While larvae of the Indian meal moths (P. interpunctella) appeared to be able to chew on and eat polyethene (PE) films, two bacterial strains capable of degrading PE were detected in their gut. The bacterial strains were able to reduce the molecular weight of the $\mathrm{PE}$, and they released 12 water-soluble products of the PE foils (Yang et al., 2014). The yellow mealworm (T. molitor) is able to consume and degrade (i.e. depolymerisation and oxidation) polystyrene (PS), probably due to the presence of PS degrading bacteria in their gut (Yang et al., 2015a,b, 2018). This degradation of plastic materials is interesting, but such knowledge is lacking with respect to BSFL.

Research of Poma et al. (2019) provides more insight into the accumulation of organic compounds (e.g. plasticisers, flame retardants, etc.) in various edible insects (i.e. A. domesticus, L. migratoria, T. molitor, Bombyx mori, Cryptotympana atrata, Pantala flavescens, Verspula flaviceps, Protaetia brevitarsis, Oxya japonica and Nemobius sylvestris). Poma et al. (2019) found insects (e.g. A. domesticus, T. molitor, etc.) contaminated with for instance bis(2-ethylhexyl) phthalate which indicates the potential contamination of these chemicals likely after harvesting, but this was not yet investigated with respect to BSFL (Poma et al., 2019).

Persistent organic pollutants (POPs), including dichlorodiphenyltrichloroethane, aldrin, dioxins, polychlorinated biphenyls (PCBs), etc. are another important group of compounds to consider when assessing the chemical safety of reared BSFL. POPs are lipophilic, they are hard to degrade in the environment, and they can easily accumulate in the insect's fat body (Jackson et al., 2017). Charlton et al. (2015) obtained insect samples from a range of countries and analysed the presence of several chemical contaminants (e.g. dioxins, PCBs, and polycyclic aromatic hydrocarbons) in various insect species including BSFL. It appeared that all investigated compounds were below the detection limit. Unfortunately, the content of the investigated contaminants in the rearing substrates was not mentioned. As no other studies have been done according to our literature survey on the influence of POPs on BSFL, many questions still remain about their influence on larval growth and/or their accumulation in BSFL. 


\section{Recommendations for future research}

The need for more sustainable protein sources and the processing of organic waste streams with limited nutritional losses are two issues that are attracting considerable attention. Research on BSFL reared on organic waste streams has the potential to address both challenges, and the current body of evidence, as reviewed in this publication, illustrates that in general most chemical risks explored so far are manageable. However, it is still too early to finalise a chemical risk assessment as some clear gaps still remain for further investigation.

Metals may induce immunotoxicity, but these effects are not studied on BSFL. Since BSFL growth is barely affected by metals, it can be assumed that their immune system has developed a mechanism to prevent the adverse effects of several metals. Further research should focus on the variations in haemocytes to study this more in depth.

As for metals, data on the accumulation of several pesticides has already been published. However, other insect species (e.g. Drosophila melanogaster) are able to degrade such chemicals (i.e. imidacloprid) into different compounds (Hoi et al., 2014). More data to explore if these mechanisms are also present in BSFL and, if so, which products are produced is also a key for the risk assessment of BSFL. To explore the chemical safety of BSFL exposed to pesticides, studies can be initiated to investigate relevant hazardous substances for each pesticide class mentioned by the World Health Organisation as extremely or highly hazardous pesticides (Council on Scientific Affairs, 1997; WHO/IPCS, 2004, 2010. The same applies for other product categories that contain molecules which potentially cause health issues, like POPs and pharmaceuticals. In addition, to valorise organic waste streams, further research is also required regarding (micro)plastics and their accompanying additives to make a correct risk assessment. Since some insect species (e.g. insects of the Coleoptera order) appear to accumulate plastic additives (e.g. bis(2-ethylhexyl) phthalate) (Poma et al., 2019), the potential accumulation of these compound classes in BSFL needs to be investigated. Exposure studies are required to investigate the influence of these chemicals on BSFL and to assess their bioaccumulation patterns.

Research should also focus on the degradation and excretion mechanisms of chemical compounds. If degradation is observed, researchers should bear in mind that both the larvae and/or their associated micro-organisms present in the gastrointestinal tract and/or the rearing substrate might be responsible for the degradation, in the same way as established in other insect species (T. molitor and $P$. interpunctella) (Yang et al., 2014, 2015a,b). In order to investigate thoroughly the degradation mechanism of compounds potentially mediated by BSFL, microbiological and both qualitative and quantitative chemical analyses need to be performed because BSFL might be able to metabolise several compounds resulting in a less traceable amount of the initial compound.

Another relevant topic is the research on the epigenetic effects of hazardous chemicals, which reflect the effect of such chemicals on successive BSFL generations. If BSFL are reared on substrates containing specific chemicals, the next generations might develop a mechanism to survive and thrive better on such substrates. Furthermore, certain substances, such as insecticides, may adversely affect the reproduction and/or growth of subsequent BSFL generations. Hence, future studies will have to take these effects into account by performing exposure studies on consecutive BSFL generations.

One last aspect to be tackled in future studies is the lack of data concerning the combined effects of multiple compounds. It is not only relevant to investigate the influence of individual substances on the larvae, but also common combinations of these substances because of potential synergistic or antagonistic effects. Exposure studies need to be executed by spiking combined chemicals to the substrate and assess the effect of them on the BSFL either for growth, survival rate and bioaccumulation.

\section{Conclusions}

The next years will be vital to exploit the potential of BSFL as a waste converter, protein source for feed, and as a source of various biochemicals (e.g. proteins, fats, chitin, etc.). This review article presents the current body of literature about the chemical safety of BSFL as well as the existing gaps and recommendations for future research. Even though the influence of some hazardous chemical compounds (i.e. metals, mycotoxins, pesticides, and pharmaceutical compounds) has already been investigated, substantial information is still lacking in order to exploit the full potential of BSFL if reared on organic waste streams. Overall, it appears that BSFL are not affected by the presence of the investigated chemical compounds in terms of growth performance and survival rate except for cyromazine and pyriproxyfen, but the cause of whether there is an effect has not yet been determined. In addition, the concentration of a few metals in the BSFL (i.e. cadmium, lead, and zinc) were above the maximum limits according to the European feed legislation impending the chemical safety. As a result, the amount of the compounds, that can accumulate into the BSFL, should be monitored in the substrate prior to the decision of whether to use such waste streams to feed BSFL. If more results are available concerning the chemical safety of BSFL, the legislation could be aligned with these results and organic waste streams that appear to be safe and that are currently under-utilised could be upgraded and used as insect feed. 


\section{Acknowledgements}

This work was supported by the FWO (Research Foundation - Flanders) under grant agreement S008519N (ENTOBIOTA). S.L. acknowledges the provision of a doctoral fellowship from the KU Leuven and the University of Antwerp. G.P. and J.D.S. acknowledge a post-doctoral fellowship from the University of Antwerp and FWO, respectively. Lastly, we thank Mr Tjebbe Lievens and Ms Marie Van Baelen, who ensured the graphical design and proofread the manuscript, respectively.

\section{Conflict of interest}

The authors declare no conflict of interest.

\section{References}

Abduh, M.Y., Nadia, M.H., Syaripudin, Manurung, R. and Putra, R.E., 2018. Factors affecting the bioconversion of Philippine tung seed by black soldier fly larvae for the production of protein and oil-rich biomass. Journal of Asia-Pacific Entomology 21: 836-842. https:// doi.org/10.1016/j.aspen.2018.06.007

Adhikari, M., Negi, B., Kaushik, N., Adhikari, A., Al-Khedhairy, A.A., Kaushik, N.K. and Choi, E.H., 2017. T-2 mycotoxin: toxicological effects and decontamination strategies. Oncotarget 8: 33933-33952. https://doi.org/10.18632/oncotarget.15422

Al-Qazzaz, M.F.A., Ismail, D., Akit, H. and Idris, L.H., 2016. Effect of using insect larvae meal as a complete protein source on quality and productivity characteristics of laying hens. Revista Brasileira de Zootecnia 45: 518-523. https://doi.org/10.1590/S180692902016000900003

Barona, E., Ramankutty, N., Hyman, G. and Coomes, O.T., 2010. The role of pasture and soybean in deforestation of the Brazilian Amazon. Environmental Research Letters 5: 1-9. https://doi. org/10.1088/1748-9326/5/2/024002

Biancarosa, I., Liland, N.S., Biemans, D., Araujo, P., Bruckner, C.G., Waagbø, R., Torstensen, B.E., Lock, E.J. and Amlund, H., 2018. Uptake of heavy metals and arsenic in black soldier fly (Hermetia illucens) larvae grown on seaweed-enriched media. Journal of the Science of Food and Agriculture 98: 2176-2183. https://doi. org $/ 10.1002 /$ jsfa.8702

Borowska, J. and Pyza, E., 2011. Effects of heavy metals on insect immunocompetent cells. Journal of Insect Physiology 57: 760-770. https://doi.org/10.1016/j.jinsphys.2011.02.012

Bosch, G., Van Der Fels-Klerx, H.J., De Rijk, T.C. and Oonincx, D.G.A.B., 2017. Aflatoxin B1 tolerance and accumulation in black soldier fly larvae (Hermetia illucens) and yellow mealworms (Tenebrio molitor). Toxins 9: 1-10. https://doi.org/10.3390/ toxins 9060185

Brandon, A.M., El Abbadi, S.H., Ibekwe, U.A., Cho, Y.M., Wu, W.M. and Criddle, C.S., 2019. Fate of hexabromocyclododecane (HBCD), a common flame retardant, in polystyrene-degrading mealworms: elevated HBCD levels. Environmental Science \& Technology 54: 364-371. https://doi.org/10.1021/acs.est.9b06501
Bulak, P., Polakowski, C., Nowak, K., Waśko, A., Wiącek, D. and Bieganowski, A., 2018. Hermetia illucens as a new and promising species for use in entomoremediation. Science of the Total Environment 633: 912-919. https://doi.org/10.1016/j. scitotenv.2018.03.252

Caligiani, A., Marseglia, A., Leni, G., Baldassarre, S., Maistrello, L., Dossena, A. and Sforza, S., 2018. Composition of black soldier fly prepupae and systematic approaches for extraction and fractionation of proteins, lipids and chitin. Food Research International 105: 812820. https://doi.org/10.1016/j.foodres.2017.12.012

Canady, R.A., Coker, R.D., Egan, K.S., Krska, R., Olsen, M., Resnik, S. and Schlatter, J., 2001. T-2 and HT-2 toxins. Joint FAO/WHO Expert Committee on Food Additives, Safety Evaluation of Certain Mycotoxins in Food, International Program of Chemical Safety, WHO Food Additives series 47: 557-680. Available at: http://www. inchem.org/documents/jecfa/jecmono/v47je06.htm.

Charlton, A.J., Dickinson, M., Wakefield, M.E., Fitches, E., Kenis, M., Han, R., Zhu, F., Kone, N., Grant, M., Devic, E., Bruggeman, G., Prior, R. and Smith, R., 2015. Exploring the chemical safety of fly larvae as a source of protein for animal feed. Journal of Insects as Food and Feed 1: 7-16. https://doi.org/10.3920/jiff2014.0020

Čičková, H., Newton, G.L., Lacy, R.C. and Kozánek, M., 2015. The use of fly larvae for organic waste treatment. Waste Management 35: 68-80. https://doi.org/10.1016/j.wasman.2014.09.026

Council on Scientific Affairs, 1997. Educational and informational strategies to reduce pesticide risks. Preventive Medicine 26: 191200. https://doi.org/101006/pmed.1996.0122

Craig, S., Helfrich, L., Kuhn, D.D. and Schwarz, M.H., 2017. Understanding fish nutrition, feeds, and feeding. Virginia Cooperative Extention, Blacksburg, VA, USA. Available at: https:// www.pubs.ext.vt.edu/FST/FST-269/FST-269.html.

Cullere, M., Tasoniero, G., Giaccone, V., Acuti, G., Marangon, A. and Dalle Zotte, A., 2018. Black soldier fly as dietary protein source for broiler quails: meat proximate composition, fatty acid and amino acid profile, oxidative status and sensory traits. Animal 12: 640-647. https://doi.org/10.1017/S1751731117001860

Da Silva, G.D.P. and Hesselberg, T., 2020. A review of the use of black soldier fly larvae, Hermetia illucens (Diptera: Stratiomyidae), to compost organic waste in tropical regions. Neotropical Entomology 49: 151-162. https://doi.org/10.1007/s13744-019-00719-z

De Paepe, E., Wauters, J., Van Der Borght, M., Claes, J., Huysman, S., Croubels, S. and Vanhaecke, L., 2019. Ultra-high-performance liquid chromatography coupled to quadrupole orbitrap high-resolution mass spectrometry for multi-residue screening of pesticides, (veterinary) drugs and mycotoxins in edible insects. Food Chemistry 293: 187-196. https://doi.org/10.1016/j.foodchem.2019.04.082

De Smet, J., Wynants, E., Cos, P. and Van Campenhout, L., 2018. Microbial community dynamics during rearing of black soldier fly larvae (Hermetia illucens) and impact on exploitation potential. Applied and Environmental Microbiology 84: 1-17. https://doi. org/10.1128/AEM.02722-17

Diclaro, J. W. and Kaufman, P.E., 2009. Black soldier fly Hermetia illucens Linnaeus (Insecta: Diptera: Stratiomyidae). EENY no. 461. UF/IFAS Extension, Gainesville, FL, USA, 4 pp. Available at: https:// edis.ifas.ufl.edu/in830. 
Diener, S., Zurbrügg, C. and Tockner, K., 2009. Conversion of organic material by black soldier fly larvae: establishing optimal feeding rates. Waste Management and Research 27: 603-610. https://doi. org/10.1177/0734242X09103838

Diener, S., Zurbrügg, C. and Tockner, K., 2015. Bioaccumulation of heavy metals in the black soldier fly, Hermetia illucens and effects on its life cycle. Journal of Insects as Food and Feed 1: 261-270. https://doi.org/10.3920/jiff2015.0030

Elieh-Ali-Komi, D. and Hamblin, M.R., 2016. Chitin and chitosan: production and application of versatile biomedical nanomaterials. International Journal of Advanced Research (Indore) 4: 411-427. https://doi.org/10.2307/4145104

Environmental Protection Agency, 2020. Sustainable materials management: non-hazardous materials and waste management hierarchy. United States Environmental Protection Agency, Washington, DC, USA. Available at: https://www.epa.gov/smm/ sustainable-materials-management-non-hazardous-materials-andwaste-management-hierarchy.

European Commission, 2001. Regulation (EC) No 999/2001 of the European Parliament and of the council of 22 May 2001 laying down rules for the prevention, control and eradication of certain transmissible spongiform encephalopathies. Official Journal of the European Union 147, 1-110. Available at: http://data.europa. eu/eli/reg/2001/999/oj.

European Commission, 2002. Directive 2002/32/EC of the European Parliament and of the council of 7 May 2002 on undesirable substances in animal feed. Official Journal of the European Union 140: 10-21. Available at: http://data.europa.eu/eli/dir/2002/32/oj.

European Commission, 2006. Commission recommendation of 17 August 2006 on the presence of deoxynivalenol, zearalenone, ochratoxin A, T-2 and HT-2 and fumonisins in products intended for animal feeding. Official Journal of the European Union 229: 7-9. Available at: http://data.europa.eu/eli/reco/2006/576/oj.

European Commission, 2009. Regulation (EC) No 767/2009 of the European Parliament and of the Council of 13 July 2009 on the placing on the market and use of feed, amending European Parliament and Council Regulation (EC) No 1831/2003 and repealing Council Directive 79/373/EEC, commission directive 80/511/EEC, council directives 82/471/EEC, 93/74/EEC, 93/113/ EC and 96/25/EC and commission decision. Official Journal of the European Union 229: 1-28. Available at: http://data.europa.eu/eli/ reg/2009/767/oj.

European Commission, 2013. Commission regulation (EU) No 1275/2013 of 6 December 2013 amending annex I to directive 2002/32/EC of the European Parliament and of the Council as regards maximum levels for arsenic, cadmium, lead, nitrites, volatile mustard oil and harmful botanical impurities. Official Journal of the European Union 328: 86-92. Available at: http://data.europa. eu/eli/reg/2013/1275/oj.
European Commission, 2016a. Commission implementing regulation (EU) 2016/1095 of 6 July 5612016 concerning the authorisation of zinc acetate dihydrate, zinc chloride anhydrous, zinc 562 oxide, zinc sulphate heptahydrate, zinc sulphate monohydrate, zinc chelate of amino acids 563 hydrate, zinc chelate of protein hydrolysates, zinc chelate of glycine hydrate (solid) and zinc 564 chelate of glycine hydrate (liquid) as feed additives for all animal species and amending 565 regulations (EC) no 1334/2003, (EC) no 479/2006, (EU) no $335 / 2010$ and implementing 566 regulations (EU) no 991/2012 and (EU) no 636/2013. Official Journal of the European Union 182: 7-27. Available at: http://data.europa.eu/eli/reg_impl/2016/1095/oj. European Commission, 2016b. Regulation (EU) 2016/429 of the European Parliament and of the council of 9 March 2016 on transmissible animal diseases and amending and repealing certain acts in the area of animal health ('Animal Health Law'). Official Journal of the European Union 84: 1-208. Available at: http://data. europa.eu/eli/reg/2016/429/oj.

European Commission, 2017. Commission regulation (EU) 2017/893 of 24 May 2017 amending annexes I and IV to regulation (EC) No 999/2001 of the European Parliament and of the council and annexes $\mathrm{X}, \mathrm{XIV}$ and XV to commission regulation (EU) No 142/2011 as regards the provisions on processed animal protein. Official Journal of the European Union 138: 92-116. Available at: http://data.europa. eu/eli/reg/2017/893/oj.

European Commission, 2019. Commission implementing regulation (EU) 2019/2007 of 18 november 2019 laying down rules for the application of regulation (EU) 2017/625 of the European Parliament and of the council as regards the lists of animals, products of animal origin, germinal products, animal by-products and derived products and hay and straw subject to official conrols at border control posts and amending decision 2007/275/EC. Official Journal of the European Union 312: 1-39. Available at: http://data.europa.eu/eli/ reg_impl/2019/2007/oj.

European Commission, 2020. EU Pesticides database. European Commission, Brussels, Belgium. Available at: https://ec.europa. eu/food/plant/pesticides/eu-pesticides-db_en

European Food Safety Authority, 2017. Scientific opinion on the potential reduction of the currently authorised maximum zinc content in complete feed. EFSA Journal 12: 1-77. https://doi. org/10.2903/j.efsa.2014.3668

Federal Agency for the Safety of the Food Chain, 2019. Insecten in diervoeders. FAVV, Brussels, Belgium. Available at: http://www. favv-afsca.fgov.be/dierlijkeproductie/dierenvoeding/insekten/.

Finke, M.D., Rojo, S., Roos, N., Van Huis, A. and Yen, A.L., 2015. The European food safety authority scientific opinion on a risk profile related to production and consumption of insects as food and feed. Journal of Insects as Food and Feed 1: 245-247. https://doi. org/10.3920/jiff2015.x006

Finke, M.D., 2013. Complete nutrient content of four species of feeder insects. Zoo Biology 32: 27-36. https://doi.org/10.1002/zoo.21012

Gao, Q., Wang, X., Wang, W., Lei, C. and Zhu, F., 2017. Influences of chromium and cadmium on the development of black soldier fly larvae. Environmental Science and Pollution Research 24: 86378644. https://doi.org/10.1007/s11356-017-8550-3 
Gold, M., Tomberlin, J.K., Diener, S., Zurbrügg, C. and Mathys, A., 2018. Decomposition of biowaste macronutrients, microbes, and chemicals in black soldier fly larval treatment: a review. Waste Management 82: 302-318. https://doi.org/10.1016/j. wasman.2018.10.022

Gulsunoglu, Z., Aravind, S., Bai, Y., Wang, L., Kutcher, H.R. and Tanaka, T., 2019. Deoxynivalenol (DON) accumulation and nutrient recovery in black soldier fly larvae (Hermetia illucens) fed wheat infected with Fusarium spp. Fermentation 5: 1-10. https://doi.org/10.3390/ fermentation5030083

Halweil, B., 2008. Meat production continues to rise. Vital Signs, Worldwatch Institute, Washington, DC, USA, pp. 15-17.

Hoi, K.K., Daborn, P.J., Battlay, P., Robin, C., Batterham, P., Hair, R.A.J.O. and Donald, W.A., 2014. Dissecting the insect metabolic machinery using twin ion mass spectrometry: a single P450 enzyme metabolizing the insecticide imidacloprid in vivo. Analytical Chemistry 86: 3525-3532. https://doi.org/10.1021/ac404188g

Hondt, E.D., Soetemans, L., Bastiaens, L., Maesen, M., Jespers, V., Van Den Bosch, B., Voorspoels, S. and Elst, K., 2020. Simplified determination of the content and average degree of acetylation of chitin in crude black soldier fly larvae samples. Carbohydrate Research 488: 1-8. https://doi.org/10.1016/j.carres.2019.107899

Imathiu, S., 2020. Benefits and food safety concerns associated with consumption of edible insects. NFS Journal 18: 1-11. https://doi. org/10.1016/j.nfs.2019.11.002

International Platform of Insects for Food and Feed, 2020. EU legislation. IPIFF, Brussels, Belgium. Available at: https://ipiff. org/insects-eu-legislation.

Jackson, E., Shoemaker, R., Larian, N. and Cassis, L., 2017. Adipose tissue as a site of toxin accumulation. Comprehensive Physiology 7: 1085-1135. https://doi.org/10.1002/cphy.c160038

Janssen, R.H., Vincken, J.P., Van Den Broek, L.A.M., Fogliano, V. and Lakemond, C.M.M., 2017. Nitrogen-to-protein conversion factors for three edible insects: Tenebrio molitor, Alphitobius diaperinus, and Hermetia illucens. Journal of Agricultural and Food Chemistry 65: 2275-2278. https://doi.org/10.1021/acs.jafc.7b00471

Kampman, B., Leguijt, C., Scholten, T., Tallat-Kelpsaite, J., Brückmann, R., Maroulis, G., Lesschen, J.P., Meesters, K., Sikirica, N. and Elbersen, B., 2017. Optimal use of biogas from waste streams: an assessment of the potential of biogas from digestion in the EU beyond 2020. European Commission, Brussels, Belgium, 158 pp. Available at: https://ec.europa.eu/energy/sites/ener/files/ documents/ce_delft_3g84_biogas_beyond_2020_final_report.pdf

Kim, Y.B., Kim, D.H., Jeong, S.B., Lee, J.W., Kim, T.H., Lee, H.G. and Lee, K.W., 2020. Black soldier fly larvae oil as an alternative fat source in broiler nutrition. Poultry Science 99: 3133-3143. https:// doi.org/10.1016/j.psj.2020.01.018

Kroeckel, S., Harjes, A.G.E., Roth, I., Katz, H., Wuertz, S., Susenbeth, A. and Schulz, C., 2012. When a turbot catches a fly: evaluation of a pre-pupae meal of the black soldier fly (Hermetia illucens) as fish meal substitute - growth performance and chitin degradation in juvenile turbot (Psetta maxima). Aquaculture 364: 345-352. https:// doi.org/10.1016/j.aquaculture.2012.08.041
Lähteenmäki-Uutela, A., Grmelová, N., Hénault-Ethier, L., Deschamps, M.H., Vandenberg, G.W., Zhao, A., Zhang, Y., Yang, B. and Nemane, V., 2017. Insects as food and feed: laws of the European Union, United States, Canada, Mexico, Australia, and China. European Food and Feed Law Review 12: 22-36. https://doi.org/10.3920/ jiff2015.x002.2

Lalander, C., Senecal, J., Gros Calvo, M., Ahrens, L., Josefsson, S., Wiberg, K. and Vinnerås, B., 2016. Fate of pharmaceuticals and pesticides in fly larvae composting. Science of the Total Environment 565: 279-286. https://doi.org/10.1016/j.scitotenv.2016.04.147

Leni, G., Cirlini, M., Jacobs, J., Depraetere, S., Gianotten, N., Sforza, S. and Dall'Asta, C., 2019. Impact of naturally contaminated substrates on Alphitobius diaperinus and Hermetia illucens: uptake and excretion of mycotoxins. Toxins 11: 476. https://doi.org/10.3390/ toxins 11080476

Li, Q., Zheng, L., Cai, H., Garza, E., Yu, Z. and Zhou, S., 2011. From organic waste to biodiesel: black soldier fly, Hermetia illucens, makes it feasible. Fuel 90: 1545-1548. https://doi.org/10.1016/j. fuel.2010.11.016

Liland, N.S., Biancarosa, I., Araujo, P., Biemans, D., Bruckner, C.G., Waagbø, R., Torstensen, B.E. and Lock, E.J., 2017. Modulation of nutrient composition of black soldier fly (Hermetia illucens) larvae by feeding seaweed-enriched media. PLoS ONE 12: 1-24. https:// doi.org/10.1371/journal.pone.0183188

Liu, S., Sun, J., Yu, L., Zhang, C., Bi, J., Zhu, F., Qu, M., Jiang, C. and Yang, Q., 2012. Extraction and characterization of chitin from the beetle Holotrichia parallela motschulsky. Molecules 17: 4604-4611. https://doi.org/10.3390/molecules17044604

Liu, X., Chen, X., Wang, H., Yang, Q., Ur Rehman, K., Li, W., Cai, M., Li, Q., Mazza, L., Zhang, J., Yu, Z. and Zheng, L., 2017. Dynamic changes of nutrient composition throughout the entire life cycle of black soldier fly. PLoS ONE 12: 1-22. https://doi.org/10.1371/ journal.pone.0182601

Makkar, H.P.S., Tran, G., Heuzé, V. and Ankers, P., 2014. Stateof-the-art on use of insects as animal feed. Animal Feed Science and Technology 197: 1-33. https://doi.org/10.1016/j. anifeedsci.2014.07.008

Maurer, V., Holinger, M., Amsler, Z., Früh, B., Wohlfahrt, J., Stamer, A. and Leiber, F., 2016. Replacement of soybean cake by Hermetia illucens meal in diets for layers. Journal of Insects as Food and Feed 2: 83-90. https://doi.org/10.3920/jiff2015.0071

Meneguz, M., Schiavone, A., Gai, F., Dama, A., Lussiana, C., Renna, M. and Gasco, L., 2018. Effect of rearing substrate on growth performance, waste reduction efficiency and chemical composition of black soldier fly (Hermetia illucens) larvae. Journal of the Science of Food and Agriculture 98: 5776-5784. https://doi.org/10.1002/ jsfa.9127

Moake, M.M., Padilla-Zakour, O.I. and Worobo, R.W., 2005. Comprehensive review of patulin control methods in foods. Comprehensive Reviews in Food Science and Food Safety 4: 8-21. https://doi.org/10.1111/j.1541-4337.2005.tb00068.x

Oliveira, F.R., Doelle, K. and Smith, R.P., 2016. External morphology of Hermetia illucens stratiomyidae: Diptera (L.1758) based on electron microscopy. Annual Research and Review in Biology 9: 1-10. https://doi.org/10.9734/ARRB/2016/22973 
Ostry, V., Malir, F., Toman, J. and Grosse, Y., 2017. Mycotoxins as human carcinogens-the IARC Monographs classification. Mycotoxin Research 33: 65-73. https://doi.org/10.1007/s12550-016-0265-7

Ottoboni, M., Spranghers, T., Pinotti, L., Baldi, A., De Jaeghere, W. and Eeckhout, M., 2018. Inclusion of Hermetia illucens larvae or prepupae in an experimental extruded feed: process optimisation and impact on in vitro digestibility. Italian Journal of Animal Science 17: 418-427. https://doi.org/10.1080/1828051X.2017.1372698

Pandey, G. and Madhuri, S., 2014. Heavy metals causing toxicity in humans, animals and environment. Research Journal of Animal, Veterinary and Fishery Sciences 2: 17-23.

Poma, G., Yin, S., Tang, B., Fujii, Y., Cuykx, M. and Covaci, A., 2019. Occurrence of selected organic contaminants in edible insects and assessent of their chemical safety. Environmental Health Perspectives 127: 1-14. https://doi.org/10.1289/EHP5782

Purschke, B., Scheibelberger, R., Axmann, S., Adler, A. and Jäger, H., 2017. Impact of substrate contamination with mycotoxins, heavy metals and pesticides on the growth performance and composition of black soldier fly larvae (Hermetia illucens) for use in the feed and food value chain. Food Additives and Contaminants: Part A 34: 1410-1420. https://doi.org/10.1080/19440049.2017.129994.

Repetto, R. and Baliga, S.S., 1997. Pesticides and immunosuppresion: the risks to public health. Health Policy and Planning 12: 97-106. https://doi.org/10.1093/heapol/12.2.97

Rohacek, J. and Hora, M., 2013. A northernmost European record of the alien black soldier fly Hermetia illucens (Linnaeus, 1758) (Diptera: Stratiomyidae). Acta Musei Silesiae Scientiae Naturales 62: 101-106. https://doi.org/10.2478/cszma-2013-0011

Shumo, M., Osuga, I.M., Khamis, F.M., Tanga, C.M., Fiaboe, K.K.M., Subramanian, S., Ekesi, S., Van Huis, A. and Borgemeister, C., 2019. The nutritive value of black soldier fly larvae reared on common organic waste streams in Kenya. Scientific Reports 9: 1-13. https:// doi.org/10.1038/s41598-019-46603-z

Smets, R., Verbinnen, B., Van De Voorde, I., Aerts, G., Claes, J. and Van Der Borght, M., 2020. Sequential extraction and characterisation of lipids, proteins, and chitin from black soldier fly (Hermetia illucens) larvae, prepupae, and pupae. Waste and Biomass Valorization 11: 6455-6466. https://doi.org/10.1007/s12649-019-00924-2

Sotnichenko, A., Pantsov, E., Shinkarev, D. and Okhanov, V., 2019. Hydrophobized reversed-phase adsorbent for protection of dairy cattle against lipophilic toxins from diet. Efficiensy in vitro and in vivo. Toxins 11: 1-21. https://doi.org/10.3390/toxins11050256

Spranghers, T., Ottoboni, M., Klootwijk, C., Ovyn, A., Deboosere, S., De Meulenaer, B., Michiels, J., Eeckhout, M., De Clerq, P. and De Smet, S., 2017. Nutritional composition of black soldier fly (Hermetia illucens) prepupae reared on different organic waste substrates. Journal of the Science of Food and Agriculture 97: 25942600. https://doi.org/10.1002/jsfa.8081

St-Hilaire, S., Sheppard, C., Tomberlin, J.K., Irving, S., Newton, L., McGuire, M.A., Mosley, E.E., Hardy, R.W. and Sealey, W., 2007. Fly prepupae as a feedstuff for rainbow trout, Oncorhynchus mykiss. Journal of the World Aquaculture Society 38: 59-67. https://doi. org/10.1111/j.1749-7345.2006.00073.x

Stamer, A., 2015. Insect proteins - a new source for animal feed. Science and Society 16: 676-680. https://doi.org/10.15252/ embr.201540528
Tabata, E., Kashimura, A., Kikuchi, A., Masuda, H., Miyahara, R., Hiruma, Y., Wakita, S., Ohno, M., Sakaguchi, M., Sugahara, Y., Matoska, V., Bauer, P.O. and Oyama, F., 2018. Chitin digestibility is dependent on feeding behaviors, which determine acidic chitinase mRNA levels in mammalian and poultry stomachs. Scientific Reports 8: 1-11. https://doi.org/10.1038/s41598-018-19940-8

Tomberlin, J.K., Sheppard, D.C. and Joyce, J.A., 2002. Susceptibility of black soldier fly (Diptera: Stratiomyidae) larvae and adults to four insecticides. Journal of Economic Entomology 95: 598-602. https://doi.org/10.1603/0022-0493-95.3.598

Tomberlin, J.K., Sheppard, D.C. and Joyce, J.A., 2006. Selected lifehistory traits of black soldier flies (Diptera: Stratiomyidae) reared on three artificial diets. Annals of the Entomological Society of America 95: 379-386. https://doi.org/10.1603/0013-8746(2002)095[0379:s] htob]2.0.co;2

Tschirner, M. and Simon, A., 2015. Influence of different growing substrates and processing on the nutrient composition of black soldier fly larvae destined for animal feed. Journal of Insects as Food and Feed 1: 249-259. https://doi.org/10.3920/jiff2014.0008

United Nations, 2017. World population projected to reach 9.8 billion in 2050, and 11.2 billion in 2100. UN, New York, NY, USA. Available at: https://www.un.org/development/desa/en/news/population/ world-population-prospects-2017.html.

Van Der Fels-Klerx, H.J., Camenzuli, L., Van Der Lee, M.K. and Oonincx, D.G.A.B., 2016. Uptake of cadmium, lead and arsenic by Tenebrio molitor and Hermetia illucens from contaminated substrates. PLoS ONE 11: 1-13. https://doi.org/10.1371/journal. pone.0166186

Vandeweyer, D., De Smet, J., Van Looveren, N. and Van Campenhout, L., in press. Biological contaminants in insects as food and feed. Journal of Insects as Food and Feed 7. https://doi.org/10.3920/ JIFF2020.0060

Verheyen, G.R., Ooms, T., Vogels, L., Vreysen, S., Bovy, A., Van Miert, S. and Meersman, F., 2018. Insects as an alternative source for the production of fats for cosmetics. Journal of Comsetic Science 69 187-202.

Wang, Y.S. and Shelomi, M., 2017. Review of black soldier fly (Hermetia illucens) as animal feed and human food. Foods 6: 91-114. https:// doi.org/10.3390/foods6100091

Weisbrod, A.V., Burkhard, L.P., Arnot, J., Mekenyan, O., Howard, P.H., Russom, C., Boethling, R., Sakuratani, Y., Traas, T., Bridges, T., Lutz, C., Bonnell, M., Woodburn, K. and Parkerton, T., 2007. Workgroup report: review of fish bioaccumulation databases used to identify persistent, bioaccumlative, toxic substances. Environmental Health Perspectives 115: 255-261. https://doi.org/10.1289/ehp.9424

Wild, C.P. and Gong, Y.Y., 2010. Mycotoxins and human disease: a largely ignored global health issue. Carcinogenesis 31: 71-82. https:// doi.org/10.1093/carcin/bgp264

World Health Organisation and International Programme on Chemical Safety (WHO/IPCS), 2004. The WHO recommended classification of pesticides by hazard and guidelines to classification 2004 . WHO, New York, NY, USA. Available at: https://apps.who.int/ iris/handle/10665/43138. 


\section{S. Lievens et al.}

World Health Organisation and International Programme on Chemical Safety (WHO/IPCS), 2010. The WHO recommended classification of pesticides by hazard and guidelines to classification 2009 . WHO, New York, NY, USA. Available at: https://apps.who.int/ iris/handle/10665/44271.

World Health Organisation (WHO), 2020. Mycotoxins. WHO, New York, NY, USA. Available at: https://www.who.int/news-room/ fact-sheets/detail/mycotoxins.

Yadav, S.K., 2010. Heavy metals toxicity in plants: an overview on the role of glutathione and phytochelatins in heavy metal stress tolerance of plants. South African Journal of Botany 76: 167-179. https://doi.org/10.1016/j.sajb.2009.10.007

Yang, J., Yang, Y., Wu, W.M., Zhao, J. and Jiang, L., 2014. Evidence of polyethylene biodegradation by bacterial strains from the guts of plastic-eating waxworms. Environmental Science \& Technology 48: 13776-13784. https://doi.org/10.1021/es504038a

Yang, S.S., Brandon, A.M., Andrew Flanagan, J.C., Yang, J., Ning, D., Cai, S.Y., Fan, H.Q., Wang, Z.Y., Ren, J., Benbow, E., Ren, N.Q., Waymouth, R.M., Zhou, J., Criddle, C.S. and Wu, W.M., 2018. Biodegradation of polystyrene wastes in yellow mealworms (larvae of Tenebrio molitor Linnaeus): factors affecting biodegradation rates and the ability of polystyrene-fed larvae to complete their life cycle. Chemosphere 191: 979-989. https://doi.org/10.1016/j. chemosphere.2017.10.117
Yang, Y., Yang, J., Wu, W. M., Zhao, J., Song, Y., Gao, L., Yang, R. and Jiang, L. 2015a. Biodegradation and mineralization of polystyrene by plastic-eating mealworms: part 1 . chemical and physical characterization and isotopic tests. Environmental Science and Technology 49: 12080-12086. https://doi.org/10.1021/acs. est.5b02661

Yang, Y., Yang, J., Wu, W. M., Zhao, J., Song, Y., Gao, L., Yang, R. and Jiang, L. 2015b. Biodegradation and mineralization of polystyrene by plastic-eating mealworms: part 2. role of gut microorganisms. Environmental Science and Technology 49: 12087-12093. https:// doi.org/10.1021/acs.est.5b02663

Yu, Z., Zheng, L., Zhang, K., Zhang, J., Ma, S., Cai, M. and Hu, R., 2017. Resistance of black soldier fly (Diptera: Stratiomyidae) larvae to combined heavy metals and potential application in municipal sewage sludge treatment. Environmental Science and Pollution Research 25: 1559-1567. https://doi.org/10.1007/s11356-017-0541-x 